\title{
Prevalence of Camel Trypanosomosis at Selected Districts of Bale Zone, Southern Ethiopia
}

\author{
Dereje Abera, Tadesse Birhanu and Tajudin Baker
}

\author{
School of Veterinary Medicine, College of Medical and Health Sciences, Wollega University,
}

Post Box No: 395, Nekemte, Ethiopia

\begin{abstract}
Across-sectional study was conducted from November 2013 to March 2014 at selected districts of Bale zone, Oromia Regional States of Ethiopia to determine the prevalence of camel trypanosmosis and assess associated potential risk factors. Simple random sampling technique was used and the study animals were selected based on the camel population of the district in the study area. The wet, thin smear and the Buffy coat examination was employed under microscope. Out of 392 examined animals, $70(17.9 \%)$ were positive for Trypanosome evansi. There was statistically significant difference between age groups, districts of the animals and trypanosome infection $(P<0.05)$. Higher prevalence of the infection was recorded in Age group of $>4$ years $(27.6 \%)$ followed by 3 years $(14.5 \%)$ and $3-4$ years old camels $(10.5 \%)$ respectively. However, there was no statistically significant difference observed between sex with the occurrence of the disease $(P>0.05)$. The highest prevalence of the disease was observed in Delo-Mena district, 42 (23.9\%) whereas the lowest was recorded in Goro district, $9(9.90 \%)$ during the study period. The result of the current study revealed that camel trypanosmosis was highly prevalent in the study area. Thus, there is need of further study on the distribution and seasonality of the disease and its vectors in order to establish effective prevention and control measures in affected herd.
\end{abstract}

Copyright@2014 STAR Journal. All Rights Reserved.

Article Information

Article History:

Received : 03-06-2014

Revised : 18-09-2014

Accepted : 20-09-2014

Keywords:

Bale Zone

Buffy coat

Camel trypanosomosis

Ethiopia

Prevalence

Smear

*Corresponding Author:

Tadesse Birhanu

E-mail:

drbirhan@yahoo.com

\section{INTRODUCTION}

In Ethiopia, camels represent a subset of major livestock resources with a population estimated at greater than 2.3 million (MOI, 2005). They play a significant multipurpose role in the arid and semi-arid parts of the country. The commonest uses of camels by the pastoralists are for transporting grain, water, salt and other goods as well as for milk and meat production. A study in Eastern Ethiopia indicated that camels work on average for 16 hours per day, traveling $60 \mathrm{~km}$ (Tefera and Gebreab, 2004). They are very reliable milk producers even during the dry season and drought years when milk from cattle and goat is scarce (Gebre and Kaaya, 2008). Camel also possess several attributes as minimum contribution to environmental degradation, utilization of scarce natural resources (feed and water), minimum competition with other ruminants and good adaptation to harsh environment.

In Ethiopia, the importance of the animal is increasing from time to time both at local and global markets. As a result, the country is earning hard currency by exporting life camels to Middle East Countries. Moreover, camel husbandry is the main source of living for millions of pastoralists in the arid and semi-arid zones of Ethiopia (MOA, 2013).Currently, due to population growth, increased frequencies of drought recurrence, shrinkage and deterioration of the rangeland by bush encroachment (grazing land for their cattle) together with increasing aridity are the major governing factor for the expansion of camels production (Biffa and Chaka, 2002). Thus camels have been indispensable alternative to cope up with the escalating rangeland ecological challenges. The animal is a more reliable milk provider than other classes of livestock in arid areas, during both dry seasons and drought years. There is also an increasing demand for camel milk and meat in local market (MOA, 2013).

Even though the livestock sub sector contributes much to the national economy, its development is hampered by different constraints (PACE, 2003). The most important constraints to camel productions are widespread diseases, poor veterinary service and lack of attention from government. Camels are believed to be comparatively less susceptible to many diseases that affect other livestock species. However, they are still affected by many endemic diseases (Dirie and Abdurahman, 2003). Some pilot studies conducted showed that the occurrence and severity of diseases varies with seasons, animal groups and camel herding ethnics (Megersa, 2010).

Among the diseases constraints, camel trypanosmosis is continues to be the major problem in sub-Saharan African countries including Ethiopia (Donelson, 2003). It has numerous negative impacts on productivity and fertility of herds i.e. losses due to mortality and morbidity, 
loss of weight, depressed growth, poor fertility performance, decrease physical power and the likes (CACC, 2003). Pastoralist community have been marginalized for long period of time, geographically found at periphery and harsh environment that hinder proper interventions and available technology transfer; the animal production and management problems prevailing in the area become very poor. Additionally, the impact of the diseases is exacerbated due to the poor veterinary service availability in the pastoralist areas (Assegid, 2000). A study conducted in southern Ethiopia indicates that Trypanosoma is one of the leading health problems (Tefera and Gebreab, 2004).

Despite all its ecological, economic importance and significant role in the life of pastoral community, until recently the animals were neglected by researchers and development planners in Ethiopia. Moreover, there is no well documented information about camel trypanosmosis and associated risk factors in Bale Zone, southern Ethiopia. Thus, the study was designed to determine the prevalence of camel trypanosmosis and assess potential associated risk factors at the selected districts of the study area.

\section{MATERIALS AND METHODS}

\section{Study Area}

The study was conducted at selected districts of Bale zone, Oromia Regional States. The district is located at $555 \mathrm{~km}$ south west from Addis Ababa, capital city of Ethiopia. The average annual temperature ranges between $27-33^{\circ} \mathrm{C}$, the area has two rain seasons with the main rainy season from March to May and the small rainy season from September to November. The livestock population of the district comprise about 276318 cattle, 5246 sheep, 55742 goat, 12582 donkey, 2452 Horse, 9465 mules, 34957 Camel and 36946 Poultry (CSA, 2009).

\section{Study Population}

The study animals were indigenous one hump camel which varies with age, sex and district that reared under extensive husbandry system. The camels of different districts of the Bale Zone such as Sawena, Delo-Mena and Goro districts were included during the study period.

\section{Study Design}

Across-sectional study was conducted from November 2013 to March 2014 in the study areas to determine the prevalence of camel trypanosmosis and assess associated potential risk factors in the study area.

\section{Sampling and Sample Size Determination}

Simple random sampling technique was used to select the study animals for blood sample collection in the study area. The districts considered as primary unit, the herds as secondary units and individual animals as tertiary units. Camel herd in three (3) were sampled during the study based on the camel population of the district. In order to determine the desired sample size the previous reports of prevalence in the Delo-Mena district was considered as expected prevalence. The expected prevalence rate was $72 \%$ for the area within 95\% confidence intervals $(\mathrm{Cl})$ at $5 \%$ desired accuracy as stated (Thrusfield, 2007).

$$
\mathbf{n}=\frac{1.96^{2}(\mathbf{p})(1-\mathbf{p})}{\mathbf{d}^{2}}
$$

Where $\mathrm{n}=$ sample size

\section{$\mathrm{p}=$ Expected prevalence \\ $d=$ Desired level of precision $(5 \%)$}

However, the sample size was 310 to increase the representativeness of the samples to the wider population. Hence, $\mathrm{n}=392$ camel were sampled. Sampling was proportionally distributed based on the camel population in the study district.

\section{Study Methodology}

The whole blood samples were collected from 392 camels by puncturing jugular vein into $5 \mathrm{ml}$ ethylene tetraacetic acid (EDTA) coated vacutainer tubes then kept in cooler box and transported to Goba Veterinary Clinic Laboratory for lab activities. Then, the tube was sealed and heparinized capillary tube containing blood was centrifuged for 5 minutes at 12,000 revolutions per minute. After the centrifugation, tubes were then placed in hematocrit reader and recorded for each sample. Then, the readings were expressed as a percentage of packed red cells to the total volume of whole blood. Animals with Packed Cell Volume (PCV < 25\%) were considered to be anaemic (Morag, 2002). Trypanosomes were usually found in or just above Buffy coat layer. So, capillary tube was cut using a diamond tipped pen $1 \mathrm{~mm}$ below the Buffy coat to include the upper most layers of the red blood cells and $3 \mathrm{~mm}$ above to include the plasma. The content of the capillary tube was expressed on to slide, homogenized on to a clean glass slide and covered with cover slip. The slide was examined under 40x objective and 10x eye pieces for the movement of parasite. The species were identified based on the characteristic the morphology of Trypanosomes (Paris et al., 1982).

For wet film, a drop of blood was placed on a clean glass slide and covered with cover slip, allowing the blood to spread as a thin layer of cells then examined under microscope to observe the motile trypanosomes. Thin and thick blood smear were made as per method described by (Murray et al., 1979). The air dried smears were fixed in absolute methylene alcohol for 2-3minutes. The slides were immersed in Geimsa stain for 20-25 and washed with tape water to remove excess stain. After air drying, the slides were examined under oil immersion objective lens (100x) for detection and identification of trypanosome species based on their morphological characters (Murray et al., 1979).

\section{Data Analysis}

The collected data from the field and parasitological examination results was inserted into a computer on a Microsoft Excel 2007 spreadsheet. Statistical analysis was performed using 'Statistical Package for the Social Sciences' (SPSS) version 20. Descriptive statistics was used to determine the prevalence of the disease and any association between the disease and associated risk factors (age, sex and origins). In all the analysis, confidence level was held at $95 \%$ and $\mathrm{P}<0.05$ was set for significance.

\section{RESULTS}

Out of 392 examined animals, 70 (17.9\%) were positive for $T$. evansi. No other trypanosome species were detected. Higher trypanosome infection was recorded in age group of $>4$ years $(27.63 \%)$ followed by 3 years $(14.5 \%)$ and $3-4$ years old camels $(10.5 \%)$ respectively. There was statistically significant difference $(P<0.05)$ between different age groups (Table 1). 
Dereje Abera et al.,

Out of the total examined camels, $16(20.3 \%)$ and $56(17.7 \%)$ animals were positive for male and female respectively. Sex-wise analysis reveals that there was no statistical significant difference in prevalence $(P<0.05)$ (Table 2).
Sci. Technol. Arts Res. J., July-Sep 2014, 3(3): 103-106

In this finding, Trypanosome evensi infection was found in all the three examined districts. The highest prevalence $42(23.9 \%)$ of the disease was recorded in Delo-Mena whereas the lowest prevalence 9 (9.90\%) was at Goro district (Table 3).

Table 1: Prevalence of $T$. evensi among age groups in the study area

\begin{tabular}{ccccc}
\hline Age & $\begin{array}{c}\text { Number of Animals } \\
\text { Examined }\end{array}$ & $\begin{array}{c}\text { Number of } \\
\text { +Ve Animals }\end{array}$ & Prevalence (\%) & P-value \\
\hline <3years & 110 & 16 & $14.5 \%$ & \\
3-4 years & 131 & 14 & $10.5 \%$ & 0.00 \\
$>4$ years & 151 & 40 & $26.5 \%$ & \\
\hline Total & $\mathbf{3 9 2}$ & $\mathbf{7 0}$ & $\mathbf{1 7 . 9 \%}$ &
\end{tabular}

Table 2: Prevalence of $T$. evensi between sexes in the study area

\begin{tabular}{ccccc}
\hline Sex & $\begin{array}{c}\text { Number of Animals } \\
\text { Examined }\end{array}$ & $\begin{array}{c}\text { Number of } \\
{ }^{+} \text {Ve Animals }\end{array}$ & Prevalence (\%) & P-value \\
\hline Male & 79 & 16 & $20.3 \%$ & 0.06 \\
Female & 313 & 54 & $17.3 \%$ & \\
\hline Total & $\mathbf{3 9 2}$ & $\mathbf{7 0}$ & $\mathbf{1 7 . 9 \%}$ & \\
\hline
\end{tabular}

Table 3: Prevalence of $T$. evensi among districts of camel in the study area

\begin{tabular}{ccccc}
\hline Districts & $\begin{array}{c}\text { Number of Animals } \\
\text { Examined }\end{array}$ & No of ${ }^{+}$Ve & Prevalence (\%) & P-value \\
\hline Sawena & 125 & 19 & $15.2 \%$ & \\
Goro & 91 & 9 & $9.90 \%$ & 0.02 \\
Delo-Mena & 176 & 42 & $23.9 \%$ & \\
\hline Total & $\mathbf{3 9 2}$ & $\mathbf{7 0}$ & $\mathbf{1 7 . 9 \%}$ & \\
\hline
\end{tabular}

\section{DISCUSSION}

The overall prevalence of camel trypanosomiasis in the study area was found to be $70(17.9 \%)$. The result was higher as compared with the findings of Tadesse et al. (2012) who reported (3.9\%) in Jijiga Zone of Somalia regional states of Ethiopia. The result of this study was also higher than the findings of Hussein (1991); Tekle and Abebe (2001); (Shah et al., 2004) who reported (13.2\%), $(10.9 \%)$ and $(10 \%)$ prevalence of $T$. evansi in Camel in Saud Arabia, Ethiopia and Pakistan respectively. This might be due to the difference in management system, season of the study period, vector density and lack awareness of the animal owners about the disease.

However, the present finding was slightly lower than the previous study of (Bogale et al., 2012) who reported $72 \%$ in Delo-Mena District of Bale Zone, Oromia Region, Southwest Ethiopia. The explanation for the lower prevalence rate detected in this study could be related to distribution, challenges and density of parasite vector as well as vector control management practice (Ford and Katondo, 1977).

In this study, age-wise analysis revealed that there was statistically significant difference between age groups and the disease $(P<0.05)$ in which higher infection rate was recorded above 4 years. The result in line with other findings (Delafasse and Doutoum, 2004; Bhtto et al., 2010). The result was also in agreement with the report of Atarhouch et al. (2003) showed that the infection rate of $T$. evensi is increased with age up to maximum in the 7-10 years old age. The higher prevalence in older age camel at this stage might be due to heavy stress through their use for transportation of goods from one place to another and long-term exposure under poor management which increase the risk of infection than younger camel.

In the present study, there was no statistically significant difference observed between sex and the disease $(P>0.05)$. This might be due to all camels were equally susceptible to trypanosome infection regardless of breed and sex (Pathak and Khanna, 1995). However, higher infection rate was recorded in male $(20.3 \%)$ than female $(17.3 \%)$. This could be due to the fact that female camel was kept in house while males were used for work all the time and subject to graze out in the field. But, the result was disagrees with other findings conducted in Asia continent in which sex related differences in prevalence of the disease in camels (Shah et al., 2004) where females were more susceptible to the disease than males (15.68\%). This record might be due to stress during pregnancy and lactation which could decrease resistance in female camel and render than more susceptible to $T$. evansi infection.

In this study, there was statistically significant difference between the prevalence of camel trypanosome infection and among the three districts $(P>0.05)$. The highest prevalence of the disease was observed in DeloMena district, $42(23.9 \%)$ whereas the lowest was recorded in Goro district, $9(9.90 \%)$ during the study period. This might be due to the difference in management system, vector density, poor veterinary services, ecological difference, and lack of awareness of the animal owners about the disease.

\section{CONCLUSION}

The result of the current study revealed that camel trypanosmosis was highly prevalent in the study area. It 


\section{Dereje Abera et al.,}

was found to be the major constraints that hinder camel production and productivity so that it is a disease of major economic importance in the areas. Thus, effective prevention and control measures should be designed against the parasite and their vectors to minimize the disease. Moreover, further studies that focus on the trypanosomosis and potential associated risk factors should be conducted.

\section{ACKNOWLEDGEMENTS}

The authors would like to thank Wollega University, School of Veterinary Medicine, administrations of the Bale Zone, Goba Veterinary laboratory, animal owners and all individuals who render help during the study period.

\section{REFERENCES}

Assegid, W. (2000). Constraints to livestock and its products in Ethiopia: Policy implications. DVM thesis, Faculty of Veterinary Medicine, AddisAbaba University, Debre zeit, Ethiopia.

Atarhauch, T., Rami, M., Bendahman, M.N. and Dakkak, A. (2003). Camel trypanosomosis in Moroccol: result of first epidemiological survey. Veterinary Parasitology 111: 277286.

Bhutto, B., Gadahi, J.A., Shahl, G., Dewani, P. and Arijo, A.G. (2010). Field investigation on the prevalence of trypanosomiasis in camels in relation to sex, Age, Breed and Herd size. Pakistan Veterinary Journal 30(3): 175177.

Biffa, D. and Chaka, H. (2002). Camel and the changing system of Borana pastoral production. In: proceeding of the annual conference of the Ethiopian Veterinary Association (EVA). June 2002, Addis Ababa, Ethiopia.

Bogale, B., Kelemework, F., and Chanie, M. (2012). Trypanosmosis in Camel (Camelus dromedaries) in DeloMena District, Bale Zone, Oromia Region, Southwest Ethiopia. Acta Parasitologica Globalis 3(1): 12-15.

CASCC (2003). Central Agricultural Census Commission. Ethiopian agricultural sample enumeration, 2001/02(1994 E.C.).Results for Tigray Region. Statistical report on livestock and farm implementations. part 4, Pp 29-43.

Central Statistical Authority (CSA) (2008). Report on livestock and livestock characteristics; Volume II, Agriculture Sample Survey 2008/09.

Delafosse, A. and Doutoum, A.A. (2004). Prevalence of trypanosoma evansi infection and associated risk factors in camels in Relation to sex, Age, Breed and Herd size. Pakistan Veterinary Journal 30(3):175-177.

Dirie, M., Wallbank, K., Adem, A., Bronstein, S. and Ibrahim, M.D. (2003). Camel Trypanosomiasis and it vectors in Somalia. Veterinary Parasitology 32(4): 285-91.

Donelson, J. E., 2003. A review on antigenic variation and the African trypanosome genome. Acta Tropica 85: 391-404.

Ford, J. and Katondo, K. (1977): Maps of tsetse fly (Glosina) distribution in Africa 1973. According to sub-generic groups on scale of $1: 5,000,000$. Bulletin of animal
Sci. Technol. Arts Res. J., July-Sep 2014, 3(3): 103-106

Trypanosome evansi infection and associated risk and production in Africa, 15: 188-194.

Gebre S. and Kaaya G (2008): Prevalence of Camel ticks and haemoparasites in southern range lands of Ethiopia. Discovery Innovative 20: 10-13.

Hussein, H., Al-Asgah, N., Al- Khalifa, M. and Diab, F. (1991). The blood parasites of indigenous livestock in Saudi Arabia. Arab-Gulf Journal Science Research 9(3): 143160.

Megersa, B. (2010). An epidemiological study of major camel diseasesin the Borana lowland, Southern Ethiopia, Pp 174.

Ministry of Agriculture (MOA) (2013). Draft document on the establishment of Disease-free zones, Ministry of Agriculture, Ethiopia, $\mathrm{Pp} 23$.

Ministry of Information (MOI) (2005). Export products of Ethiopia. Press release of Ministry of Information, Department of press and audiovisual. Addis Ababa, Ethiopia.

Morag, G.K. (2002). Hematology. In Veterinary Laboratory Medicine $2^{\text {nd }}$ ed., Blackwell science, London, Pp1-25.

Murray, M, Clifford, J. and McIntyreb, W. (1979). Diagnosis of African Trypanosomiasis in bovine.Trans. Transactions of the Royal society of Tropical Medicine and Hygiene 17: 120-121.

OIE (2008). Terrestrial manual of trypanosome infection including surra: the center for food security and public health. Lowa state University, USA. Research on veterinary science, $\mathrm{Pp} 22-75$

Paris, J., Murray, M. and Mcodimba, F. (1982). A comparative evaluation of the parasitological technique available for the diagnosis of Trypanosomosis. Acta Tropica 39: 1-11.

Pathak, K. and Khanna, N. (1995). Trypanosomosis in camel (Camelus dromedarius) with particular reference to Indian sub-continent: A Review. International Journal of Animal Science 10: 157-162.

Shah, S., Phulan, M., Memon, M., Rind, R. and Bhatti, W. (2004). Tryanosomes infection in Camels. Pakistan Veterinary Journal 24(4): 209-210.

Tadesse, A., Omar, A., Aragaw, K., Mekbib, B. and Sheferaw, D. (2012). A Study on Camel Trypanosomosis in Jijiga Zone, Eastern Ethiopia. Journal of Veterinary Advances 2(5): 216-219.

Tefera, M. and Gebreab, F. (2004). A study on the productivity and diseases of Camels in Eastern Ethiopia. Tropical Animal Health and Production 33: 265-274.

Tekele, T. and Abebe, W. (2001). Trypanosomosis and helminthosis: major health problems of camels (Camelus dromedaries) in the Southern rangelands of Borena. Journal of Camel Practice Research 8(1): 180-181.

Thrusfield, M. (2007). Veterinary Epidemiology, Government Department of Navy, Bureau $3^{\text {rd }}$ UK Black well science Ltd, Pp182-198. 